\title{
Macrodystrophia Lipomatosa Extending Into the Abdominal Wall and Breast: A Case Report
}

\section{Jian Liu}

Huazhong University of Science and Technology

\section{Jiaming Sun}

Huazhong University of Science and Technology

\section{Liang Guo}

Huazhong University of Science and Technology

\section{Zhenxing Wang}

Huazhong University of Science and Technology

Nengqiang Guo ( $\sim$ guonq2012@hotmail.com )

Huazhong University of Science and Technology https://orcid.org/0000-0003-2923-7426

\section{Case Report}

Keywords: macrodystrophia lipomatosa, macromelia, congenital infiltrating lipomatosis $₫$ case report

Posted Date: October 7th, 2020

DOI: https://doi.org/10.21203/rs.3.rs-85317/v1

License: (c) (1) This work is licensed under a Creative Commons Attribution 4.0 International License. Read Full License 


\section{Abstract}

\section{Background}

Macrodystrophia lipomatosa is a rare nonhereditary congenital gigantism, characterized by overgrowth of mesenchymal and fibro-adipose tissue, affecting one or more digits of the extremities. Here, we report a rare case of macrodystrophia lipomatosa of the entire right lower limb with extension of hypertrophied fatty tissue into the abdominal wall and breast.

Case presentation

A 32 years old woman was born with abnormally elongated and thickened right leg, and the condition aggravated gradually. The disease was multiple, including the right leg, right abdominal wall, and the left breast were also involved. The patient mainly complained that she was unable to walk but with the knee flexed. Physical examination revealed that the elongation and thickening was proportional to the left leg, and the involved joints were malformed and dysfunction. X-ray and Computed tomography angiography (CTA) showed the bones and vessels were elongated and thickened, and the joints were hypertrophic and swollen. Amputation, volume reduction and liposuction was performed on the lesions. Histological examination could see abnormal fibro-fatty tissue hyperplasia, the adipocytes were invasive, and part of muscles presented fat degeneration. The lesions showed no recurrence for one year after surgery.

Conclusion

After reviewing the literature of the macrodystrophia lipomatosa, we believed that our case was rare because the hypertrophied fatty tissue extended into the abdominal wall and breast, which was different from former studies and had not been documented worldwide. This novel case will further deepens the understanding of this disease, and will be useful for clinicians in diagnosing it.

\section{Background}

Macrodystrophia lipomatosa is a rare nonhereditary developmental malformation that mainly affects fibro-adipose tissue manifesting as a form of gigantism affecting one or more digits of the hand or foot ${ }^{[1}$, 2]. In 1925, it was first described by Feriz as localized gigantism of the lower limb ${ }^{[3]}$. In 1960, the definition of this disease was further expanded to include the upper extremity by Golding ${ }^{[4]}$. Fat deposition in subcutaneous tissues, muscles as well as nerves is the characteristic feature of macrodystrophia lipomatosa ${ }^{[5]}$. Localized gigantism often has no symptoms and present with cosmetic problems ${ }^{[6]}$, but as the lesions continue to grow, it may cause secondary osteoarthritis and compression of neurovascular structures. To date, there has only been three reported cases of macrodystrophia lipomatosa involving an entire limb ${ }^{[7-9]}$. And only two cases in which abdominal wall involvement was recorded ${ }^{[8,10]}$. In our patient, the lesions involved not only the entire right lower limb, but also the right abdominal wall and left breast, which was different from former studies and had not been documented worldwide. And it is the reason we wish to report this case. 


\section{Case Presentation}

A 32 years old woman was born with abnormally elongated and thickened right leg, and the condition aggravated gradually. Because of the heavy long leg and abnormal joints, the patient was unable to walk normally but with the knee flexed. Including the right leg, the right abdominal wall, and the left breast were also involved without palpable mass. There was no related family history. The height and weight were $155 \mathrm{~cm}$ and $87 \mathrm{~kg}$, respectively. We found the elongation and thickening was proportional to the left leg, and the involved joints were malformed and dysfunction (Tab.1, Fig.1). X-ray and Computed tomography

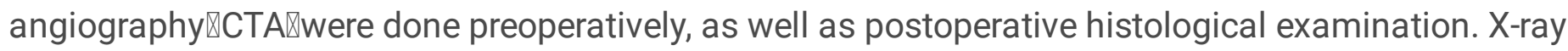
showed that all segments of right leg are obviously enlarged, pelvis is deflected, right femur, tibia and fibula are thickened, elongated and curved, osseous prominences could be seen on their ends. Tarsals and joint spaces are obscured. The ends of metacarpus and phalanges are thickened with rough borders, some joint cavities are narrowed (Fig.2). CTA showed that the vessels of right leg are smooth but abnormally elongated and thickened, without malformed vessel cluster. Cortex of femur, fibula and tibia is rough with hypertrophy, osseous prominences could be seen on the proximal ends, and the patella could not be showed. Bones of right foot are irregular, with obscured joints. Muscles of right leg are atrophied with obviously thicken adipose tissue (Fig.3). Amputation, volume reduction and liposuction was performed on the lesions. And no adverse events were observed post-operation. The extremely thickened subcutaneous adipose tissue and many thickened vessels could be seen in operation, and part of muscles present fat degeneration. Light microscope showed fibro-adipose tissue hyperplasia, which was same as the left breast and right abdominal wall. Part of the muscles were infiltrated by adipocytes, with intramuscular fatty hyperplasia, muscle fiber degeneration and loss of striation (Fig.4). In summary, the case was diagnosed as Macrodystrophia lipomatosa, which extend into the abdominal wall and breast. The lesions showed no recurrence for one year after surgery. And the patient was satisfied with the result.

Tab.1 Length and Circumference of segments of lower extremities $\square \mathrm{cm} \square$

\begin{tabular}{|lll|}
\hline & right & left \\
\hline Length of thigh & 67 & 40 \\
\hline Length of lower leg & 62 & 35 \\
\hline Length of sole & 38 & 22 \\
\hline Circumference of the middle thigh & 75 & 44 \\
\hline Circumference of the middle lower leg & 64 & 29 \\
\hline Circumference of the middle dorsal & 66 & 19 \\
\hline
\end{tabular}

\section{Discussion And Conclusions}


Unilateral macromelia could be seen in many cases such as lymphedema囚lymphangioma, neurofibromatosis, Klippel-Trenaunay-Weber syndrome, and macrodystrophia lipomatosa. In general, the clinical history and a thorough physical examination can help distinguish these entities. Lymphedema begins from the distal ends, and gradually involves the proximal part, with thickening of skin and sunken edema $^{[11]}$. Lymphangioma is a congenital benign tumor consisting lymph ducts with proliferative endothelia and fibrous tissue ${ }^{[12]}$. Neurofibromatosis is characterized by a positive family history and cafe-au-lait spots of skin. An enlarged, tortuous nerve studded by soft-tissue nodules could be checked in plexiform neurofibroma ${ }^{[13]}$. Klippel-Trenaunay-Weber syndrome could be diagnosed according to its characteristic cutaneous capillary hemangiomas and varicose veins ${ }^{[14]}$. The above diseases could cause thickening of local or total unilateral limb but elongation of limb.

According to clinical presentation $\llbracket$ this case is most similar with macrodystrophia lipomatosa. Benign fibro-fatty infiltration involving the soft tissues of the distal arm or leg is the clinical characteristic of macrodystrophia lipomatosa, with associated dactylomegaly of the associated digits. Macrodactyly initiated shortly after birth and were associated with a high incidence of anomalies including syndactyly, polydactyly, and clinodactyly. Unilateral median nerve distribution of the hands with multiple adjacent digits is more often, while a single digit could be involved, sometimes might be noted on the medial digits of the foot ${ }^{[15]}$. Histopathological characteristic is fibro-fatty tissue hyperplasia which is also similar to this patient's. However, in the involved leg of our case, both elongation and thickening were proportional to the left leg, and such extensive and huge lesion is rarely seen in former literatures. In addition, the abdominal wall and breast were also involved, which is different from former studies.

Histopathological examination of this case could see abnormal fibro-fatty tissue hyperplasia, the adipocytes were invasive, and part of muscles presented fat degeneration, which is also similar to congenital infiltrating lipomatosis $(\mathrm{CIL})$, a rare congenital disease initiating from infant ${ }^{[16]}$. Slavin et al. initially described CIL in $1983^{[17]}$. In 1987, De Rosa et al ${ }^{[18]}$. listed the main characteristics of CIL, including (1) non-encapsulated proliferation of mature fatty tissue,(2) diffused muscle and adjacent soft parts infiltration, (3)presence of fibrous tissue and increased number of vessels and nerves, (4) absence of lipoblasts or other signs of malignancy, despite the pattern and the speed of growth, (5) hypertrophy of adjacent bones and (6) congenital origin with a strong tendency of postoperative recurrence. The histopathological characteristic of this case accords with CIL and macrodystrophia lipomatosa, while CIL always involves the face but limbs. macrodystrophia lipomatosa and CIL may be the same lesion which occurred in different part of the body.

The differences of this case from the formerly reported macrodystrophia lipomatosa include:(1) The whole right leg is involved with proportional elongation and thickening, and such extensive and huge lesion is rarely seen in former literatures. (2) The adipocytes are invasive, and the part of leg muscles and pectoralis major present fat degeneration. (3) The lesions are multiple, including the right limb as well as right abdominal wall and left breast, which had not been documented worldwide. This novel case will 
further deepens the understanding of the macrodystrophia lipomatosa, and will be useful for clinicians in diagnosing it.

\section{Abbreviations}

CTA: computed tomography angiography; CIL: congenital infiltrating lipomatosis

\section{Declarations}

\section{Acknowledgements}

Not applicable

\section{Funding}

This study was funded by the National Key R\&D Program of China (2019YFA0110500)

\section{Availability of data and materials}

All data generated or analysed during this study are included in this published article.

\section{Authors' contributions}

Jian Liu is a major contributor in writing the manuscript and compiling figures. Liang Guo provided radiographic data and decription. Jiaming Sun and Zhenxing Wang helped revised the manuscript. Nengqiang Guo designed and organized the study, comfirmed the pathological analysis. This manuscript has been read and approved by all authors.

\section{Ethics approval and consent to participate}

The ethical approval and documentation for a case report was waived by the Ethical Committee of the Tongji Medical College of Huazhong University of Science and Technology.

\section{Consent for publication}

Written informed consent was obtained from the patient for the publication of this case report and any accompanying images.

\section{Competing interests}

The authors declare that they have no competing interests.

\section{References}


[1] Kozanoglu E, Koc F, Goncu K L. Macrodystrophia Lipomatosa with Multiple Entrapment Neuropathies: A Case Report[J]. International Journal of Neuroscience, 2008,118(4):545-553.

[2] Malla S, Razik A, Das C J. Macrodystrophia lipomatosa of the foot[J]. BMJ Case Reports, 2019,12(5):e229464.

[3] Feriz H. Makrodystrophia lipomatosa progressiva[J]. Virchows Archiv : an international journal of pathology, 1926,260(2):308-368.

[4] Golding F C. Rare Diseases of Bone. In: Modern Trends in Diagnostic Radiology[J]. 1960.

[5] Soler R, Rodriguez E, Bargiela A, et al. MR findings of macrodystrophia lipomatosa[J]. Clin Imaging, 1997,21(2):135-137.

[6] Brodwater B K, Major N M, Goldner R D, et al. Macrodystrophia lipomatosa with associated fibrolipomatous hamartoma of the median nerve[J]. Pediatr Surg Int, 2000,16(3):216-218.

[7] Jain R, Sawhney S, Berry M. CT diagnosis of macrodystrophia lipomatosa. A case report[J]. Acta Radiol, 1992,33(6):554-555.

[8] Fritz T R, Swischuk L E. Macrodystrophia lipomatosa extending into the upper abdomen[J]. Pediatric Radiology, 2007,37(12):1275-1277.

[9] Gao B, Zheng L P, Cai Z D. Limb salvage surgery in a patient with macrodystrophia lipomatosa involving an entire upper extremity[J]. Chin Med J (Engl), 2010,123(19):2744-2747.

[10] Aydos S E, Fitoz S, Bokesoy I. Macrodystrophia lipomatosa of the feet and subcutaneous lipomas[J]. Am J Med Genet A, 2003,119A(1):63-65.

[11] Agharbi F Z. [Lymphedema complicated with verrucous papillomatosis][J]. Pan Afr Med J, 2018,31:251.

[12] Legras A, Mordant P, Le Pimpec-Barthes F, et al. [Lymphangioma and lymphangiectasia][J]. Rev Pneumol Clin, 2013,69(5):272-277.

[13] Wagner G, Meyer V, Sachse M M. [Segmental neurofibromatosis][J]. Hautarzt, 2018,69(6):487-490.

[14] Berchiolli R, Marconi M. Klippel-Trenaunay Syndrome: A Dramatic Presentation[J]. Eur J Vasc Endovasc Surg, 2018,56(2):299.

[15] Ho C A, Herring J A, Ezaki M. Long-Term Follow-up of Progressive Macrodystrophia Lipomatosa[J]. The Journal of Bone \& Joint Surgery, 2007,89(5):1097-1102.

[16] Li Y, Chang G, Si L, et al. Congenital Infiltrating Lipomatosis of the Face[J]. Annals of Plastic Surgery, 2017:1. 
[17] Slavin S A, Baker D C, McCarthy J G, et al. Congenital infiltrating lipomatosis of the face: clinicopathologic evaluation and treatment[J]. Plast Reconstr Surg, 1983,72(2):158-164.

[18] De Rosa G, Cozzolino A, Guarino M, et al. Congenital infiltrating lipomatosis of the face: report of cases and review of the literature[J]. J Oral Maxillofac Surg, 1987,45(10):879-883.

\section{Figures}

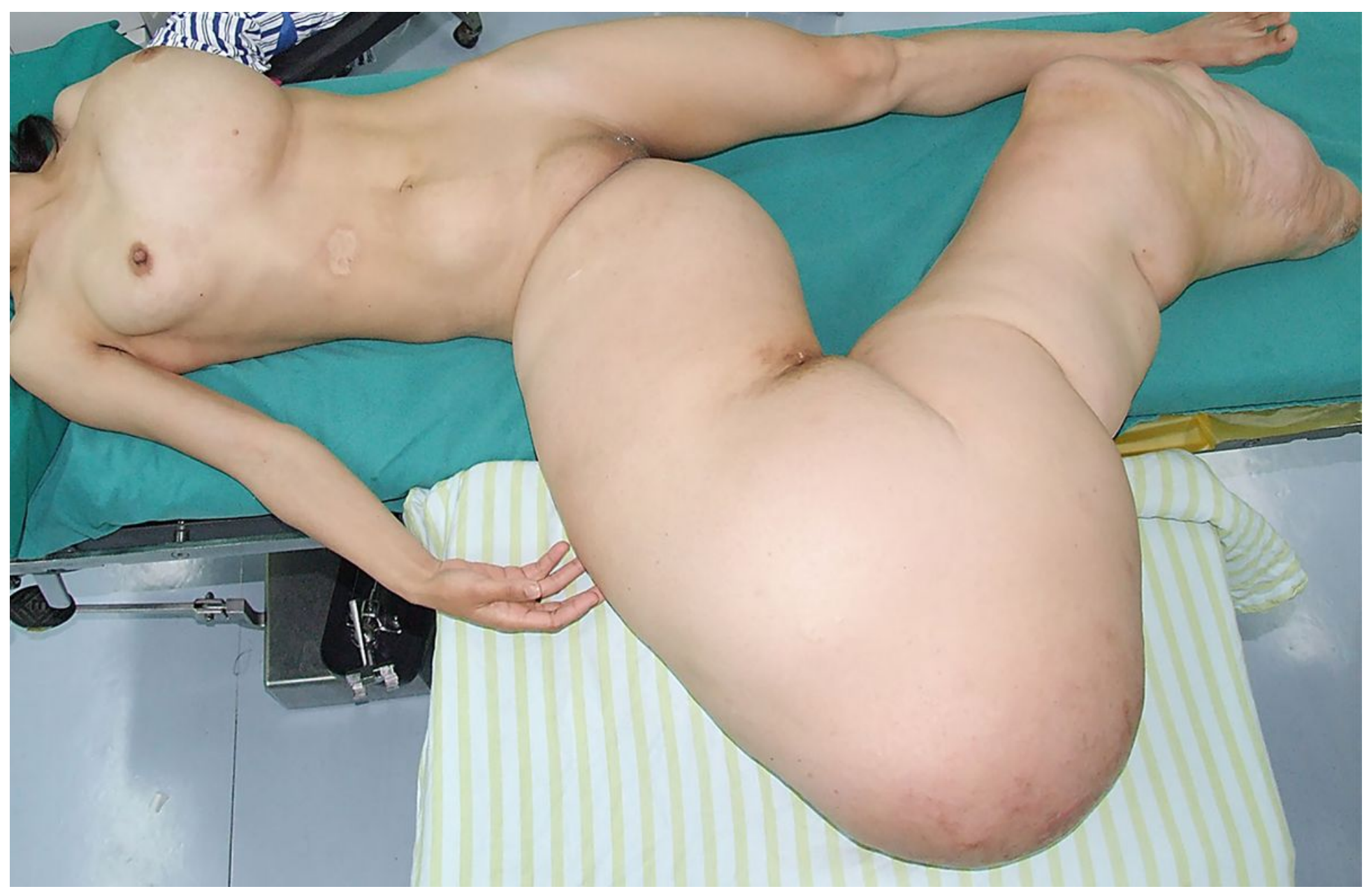

\section{Figure 1}

The left leg is normal. All segments of right leg is obviously thickened and elongated, joints are malformed and dysfunction, right lower abdomen wall is bulged, and the left breast is enlarged. 


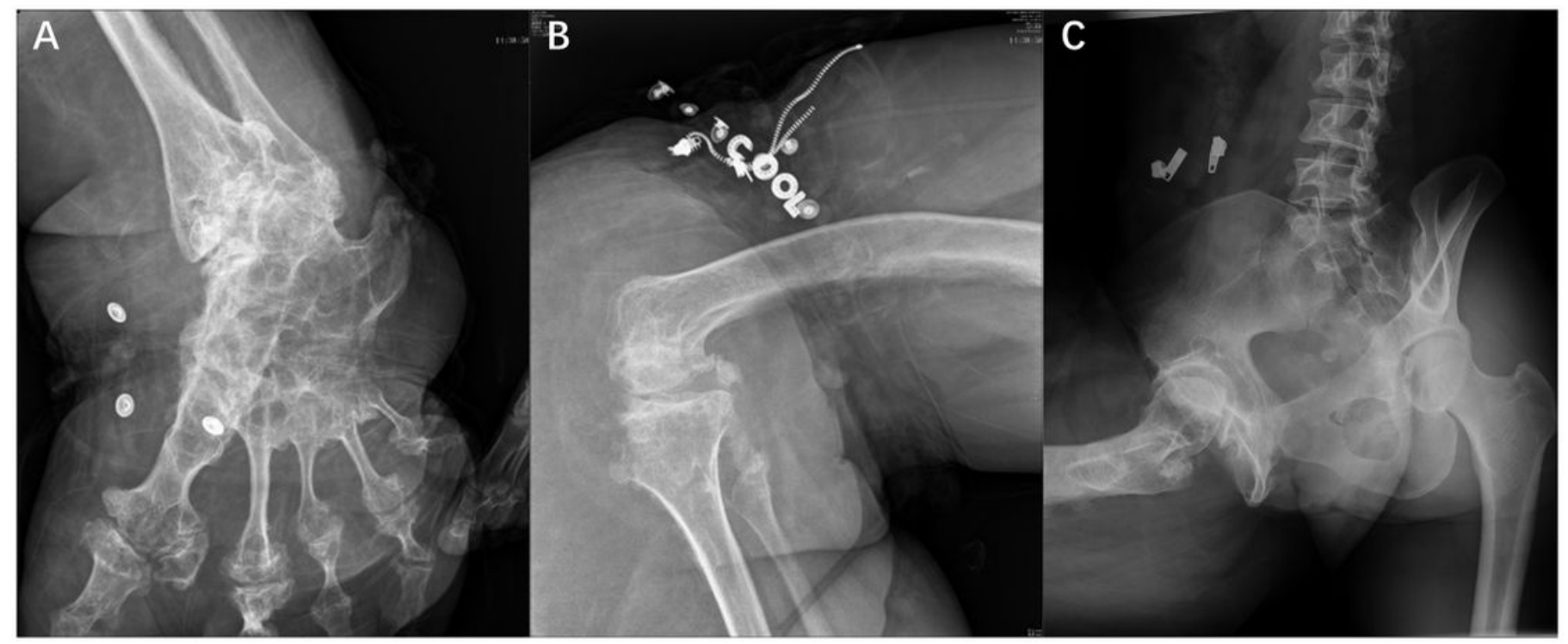

Figure 2

X-ray of right $\operatorname{leg}(A, B, C)$ :Showing abnormal changes of bones and corresponding ankle, knee, and hip joints of the right leg.

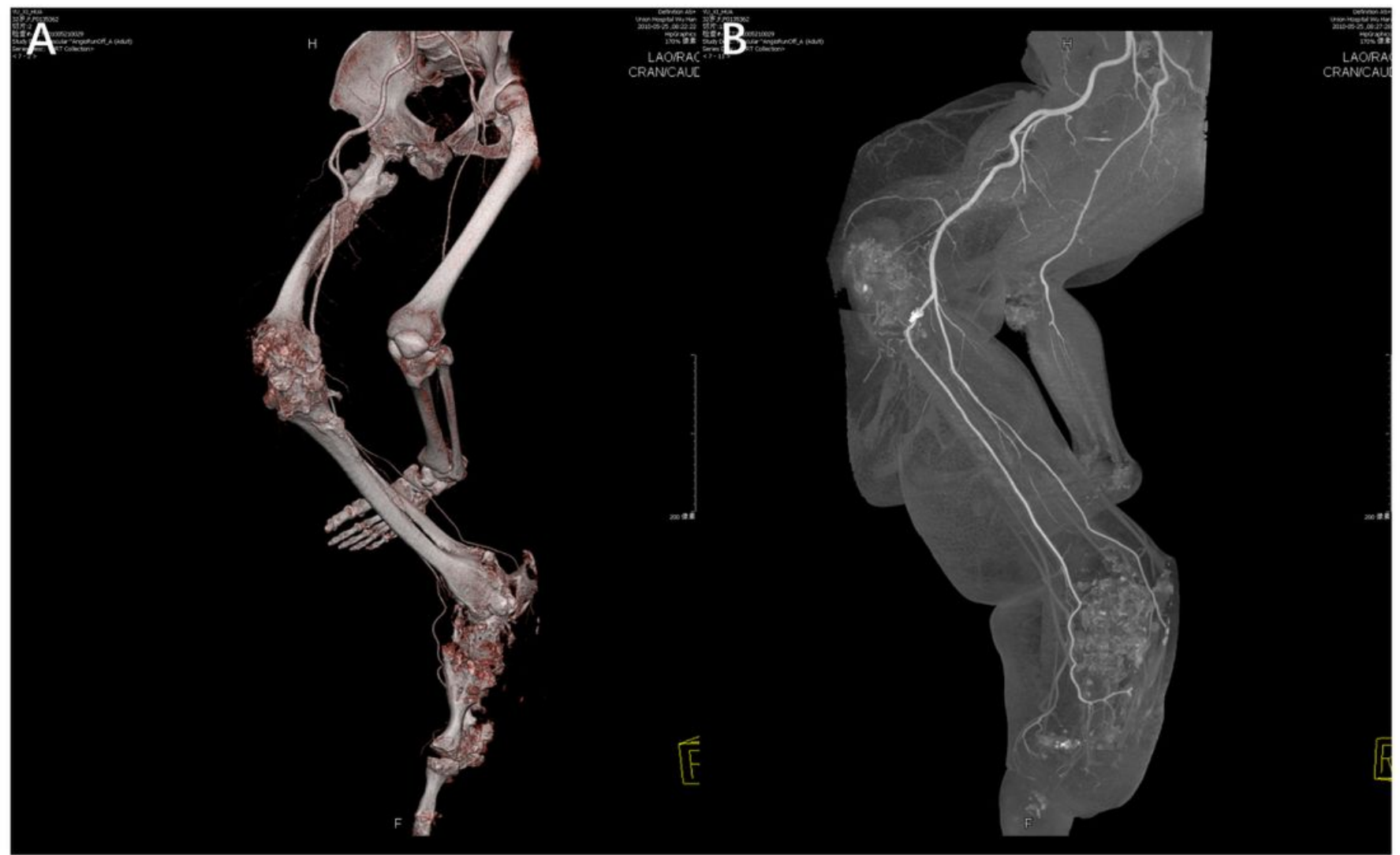

Figure 3

CTA $(A, B)$ : Showing abnormal changes in blood vessels, bones and soft tissues of the right leg. 


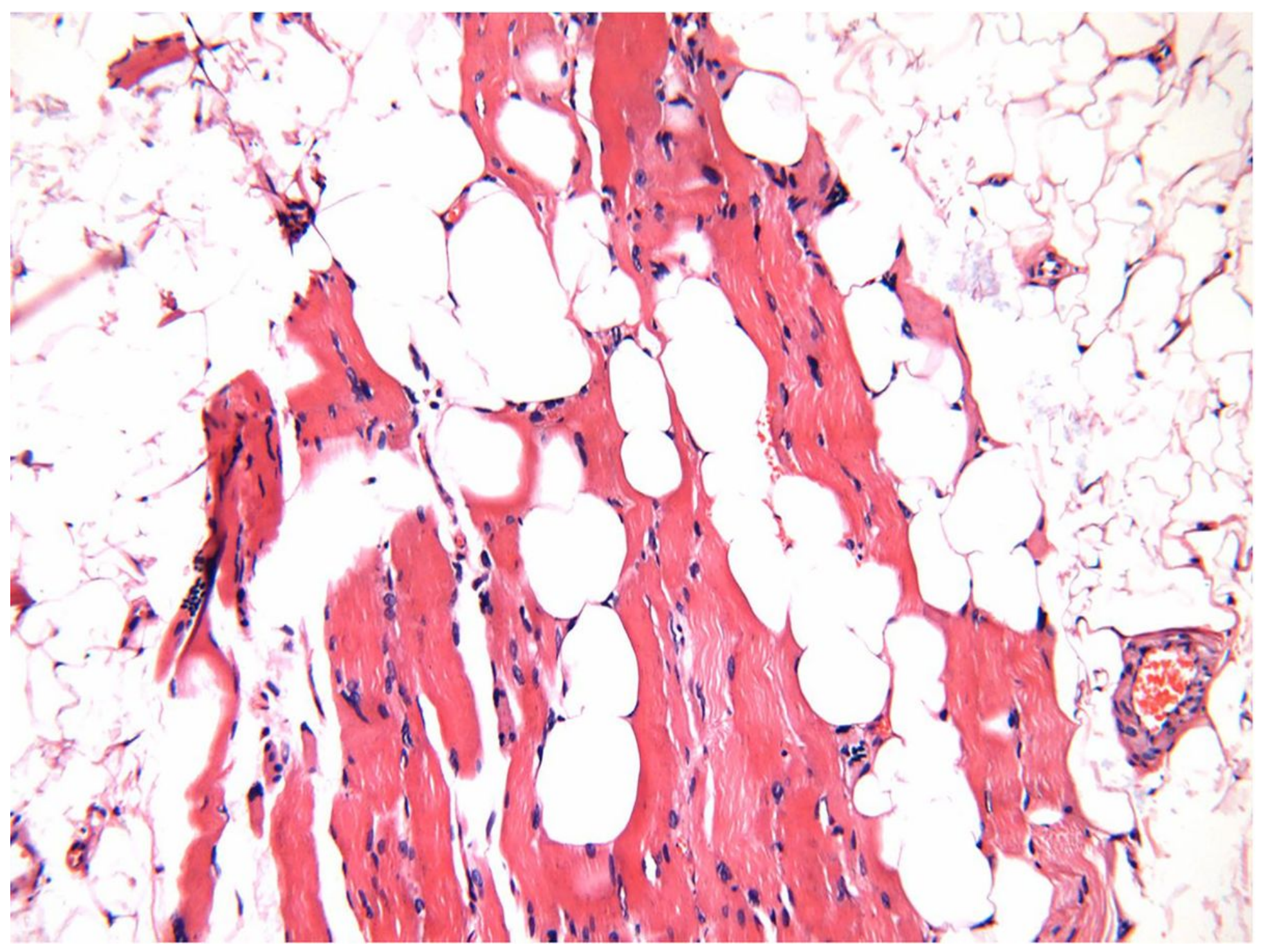

Figure 4

Histopathological examination: Photomicrograph shows hyperplasia of subcutaneous fibro-fatty tissue, mature adipocytes infiltrating between skeletal-muscle bundles, and degeneration of muscles with disappeared striation. (hematoxylin-eosin stain; original magnification, $\times 20$ )

\section{Supplementary Files}

This is a list of supplementary files associated with this preprint. Click to download.

- CAREchecklist.pdf 